\title{
Numerical solution of inviscid and viscous laminar and turbulent flow around the airfoil
}

\author{
Martin Slouka $^{1, a}$, Karel Kozel ${ }^{1,2}$ \\ ${ }^{1}$ Dept. of Technical Mathematics, Faculty of Mechanical Eng., CTU in Prague, 12135 Prague 1, Czech Rep. \\ ${ }^{2}$ Institute of Thermomechanics, Academy of Science CR, 18200 Prague 8, Czech Rep.
}

\begin{abstract}
This work deals with the $2 \mathrm{D}$ numerical solution of inviscid compressible flow and viscous compressible laminar and turbulent flow around the profile. In a case of turbulent flow algebraic BaldwinLomax model is used and compared with Wilcox k-omega model. Calculations are done for NACA 0012 and RAE 2822 airfoil profile for the different angles of upstream flow. Numerical results are compared and discussed with experimental data.
\end{abstract}

\section{Introduction}

Mathematical models used in this work are based on the solution of the inviscid compressible flow and viscous compressible laminar and turbulent flow around the airfoil.

Computational domain represents NACA 0012 and RAE 2822 airfoil profiles. The results show differences between the uses of each numerical model and experimental results.

\section{Governing equations}

The two-dimensional viscous compressible flow is prescribed by the system of Navier-Stokes equations in following conservation form

$$
\mathbf{W}_{\mathrm{t}}+\mathbf{F}_{\mathrm{x}}+\mathbf{G}_{\mathrm{y}}=\mathbf{R}_{\mathrm{x}}+\mathbf{S}_{\mathrm{x}}
$$

where

$$
\begin{aligned}
& \mathbf{W}=(\rho, \rho u, \rho v, e)^{\mathrm{T}}, \\
& \mathbf{F}=\left(\rho u, \rho u^{2}+p, \rho u v,(e+p) u\right)^{\mathrm{T}}, \\
& \mathbf{G}=\left(\rho v, \rho u v, \rho v^{2}+p,(e+p) v\right)^{\mathrm{T}}, \\
& \mathbf{R}=\left(0, \tau_{\mathrm{xx}}, \tau_{\mathrm{xy}}, u \tau_{\mathrm{xx}}+v \tau_{\mathrm{xy}}-q_{\mathrm{x}}\right)^{\mathrm{T}}, \\
& \mathbf{S}=\left(0, \tau_{\mathrm{xy}}, \tau_{\mathrm{yy}}, u \tau_{\mathrm{xy}}+v \tau_{\mathrm{yy}}-q_{\mathrm{y}}\right)^{\mathrm{T}}
\end{aligned}
$$

and

$$
\begin{aligned}
\tau_{\mathrm{ij}} & =\mu\left(\frac{\partial u_{\mathrm{i}}}{\partial x_{\mathrm{j}}}+\frac{\partial u_{\mathrm{j}}}{\partial x_{\mathrm{i}}}\right)-\frac{1}{3} \delta_{\mathrm{ij}} \frac{\partial u_{\mathrm{k}}}{\partial x_{\mathrm{k}}}, \\
q_{\mathrm{i}} & =-\frac{\kappa}{\kappa-1} \frac{\mu}{\operatorname{Pr}} \frac{\partial}{\partial x_{\mathrm{i}}}\left(\frac{p}{\rho}\right) .
\end{aligned}
$$

This system is closed by following equation

$$
p=(\kappa-1)\left[e-\frac{1}{2} \rho\left(u^{2}+v^{2}\right)\right] \text {. }
$$

In the equations above $\rho$ denotes density, $(u, v)$ are components of local velocity in $x$ and $y$ direction respectively, $e$ denotes total energy per unit volume, $p$ is pressure given by previous equation of state, $\tau_{\mathrm{ij}}$ is shear stress, $q_{\mathrm{i}}$ represents heat flux, $\mu$ represents dynamical viscosity.

Following constants were used in previous equations: $\kappa$ is isentropic exponent equalled to $1.4, \mathrm{Pr}$ is Prandtl number equalled to 0.7 .

Viscous compressible turbulent flow represents system of Reynolds averaged Navier-Stokes equations (RANS) which is formally the same as (1) with enclosed used model of turbulence which is algebraic BaldwinLomax or two-Wilcox k- $\omega$ model [1] in this work.

Inviscid flow is represented by the system of Euler equations which is simply reached after neglecting of viscosity in viscous fluxes on the right hand side in the system (1).

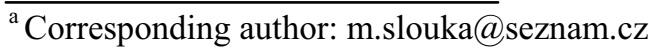




\section{Models of turbulence}

\subsection{Baldwin-Lomax model}

Baldwin-Lomax (B-L) model is the modification of basic Cebeci and Smith algebraic turbulent model. The boundary layer is divided into two regions, inner region (close to the wall) and outer region. Turbulent viscosity in the inner part is given by

$$
\mu_{\mathrm{ti}}=\rho F_{\mathrm{d}}^{2} \kappa^{2} y^{2}|\Omega|
$$

where vorticity is in $2 \mathrm{D}$ case defined as

$$
\Omega=\frac{\partial u}{\partial y}-\frac{\partial v}{\partial x}
$$

van Driest function given as follow

$$
F_{\mathrm{d}}=1-\exp \left(-\frac{1}{A} \frac{u_{\tau} y}{v_{\mathrm{w}}}\right)
$$

and friction velocity by formula

$$
u_{\tau}=\sqrt{\frac{\tau_{\mathrm{w}}}{\rho}}=\left(v \frac{\partial u}{\partial y}\right)_{\mathrm{w}}^{1 / 2} .
$$

Turbulent viscosity in outer region is given by

$$
\mu_{\mathrm{to}}=\alpha C_{\mathrm{cp}} F_{\mathrm{w}} F_{\mathrm{k}}
$$

Function $F_{\mathrm{w}}$ is determined by the relation

$$
F_{\mathrm{w}}=y_{\max } F_{\max }
$$

where $F_{\mathrm{w}}$ is the maximum of the function bellow

$$
F=y|\Omega| F_{\mathrm{d}}
$$

and $y_{\max }$ is the distance from the wall in which $F\left(y_{\max }\right)=F_{\max }$ holds and

$$
F_{\mathrm{k}}=\left[1+5.5\left(C_{\mathrm{KL}} \frac{y}{y_{\max }}\right)^{6}\right]^{-1}
$$

In Baldwin-Lomax turbulent model following constants are used: $\kappa=0.4, A=26, \alpha=0.0168, C_{\mathrm{cp}}=1.6$ and $C_{\mathrm{KL}}=0.3$.

\subsection{Wilcox k-w model}

The two-equation model is given by transport equations for two characteristic scales of turbulent motion, in this case turbulent energy $k$ and specific dissipation rate $\omega$. Then turbulent viscosity is defined as

$$
\mu_{\mathrm{t}}=\rho \frac{k}{\omega} .
$$

The Wilcox k- $\omega$ model [1] was used as follow

$$
\begin{aligned}
& \frac{\partial(\rho k)}{\partial t}+\frac{\partial\left(\rho u_{\mathrm{j}} k\right)}{\partial x_{\mathrm{j}}}=P_{\mathrm{k}}+\frac{\partial}{\partial x_{\mathrm{j}}}\left[\left(\mu+\sigma^{*} \mu_{\mathrm{t}}\right) \frac{\partial k}{\partial x_{\mathrm{j}}}\right] \\
& -\beta^{*} \rho k \omega, \\
& \frac{\partial(\rho \omega)}{\partial t}+\frac{\partial\left(\rho u_{\mathrm{j}} \omega\right)}{\partial x_{\mathrm{j}}}=\gamma \frac{\omega}{k} P_{\mathrm{k}}+\frac{\partial}{\partial x_{\mathrm{j}}}\left[\left(\mu+\sigma \mu_{\mathrm{t}}\right) \frac{\partial \omega}{\partial x_{\mathrm{j}}}\right] \\
& -\beta \rho k \omega^{2}+C_{D},
\end{aligned}
$$

where

$$
P_{\mathrm{k}}=\tau_{\mathrm{ij}} \frac{\partial u_{\mathrm{i}}}{\partial x_{\mathrm{j}}}
$$

represents production of turbulent energy and

$$
C_{\mathrm{D}}=\frac{\rho}{2 \omega} \max \left(\frac{\partial u_{\mathrm{i}}}{\partial x_{\mathrm{j}}} \frac{\partial u_{\mathrm{i}}}{\partial x_{\mathrm{j}}}, 0\right)
$$

Following model coefficients are used: $\alpha=5 / 9, \beta=3 / 40$, $\beta^{*}=9 / 100$ and $\sigma=\sigma^{*}=1 / 2$.

\section{Numerical method}

\subsection{Numerical scheme}

Finite volume method was applied on cell centred nonorthogonal structured grid with quadrilateral cells.

For numerical solutions Lax-Wendroff scheme in McCormack modification was used with predictor step

$$
\mathbf{W}_{\mathrm{i}, \mathrm{j}}^{\mathrm{n}+1 / 2}=\mathbf{W}_{\mathrm{i}, \mathrm{j}}^{\mathrm{n}}-\Delta t \operatorname{Res} \mathbf{W}_{\mathrm{i}, \mathrm{j}}^{\mathrm{n}}
$$

and corrector step as follow

$$
\mathbf{W}_{\mathrm{i}, \mathrm{j}}^{\mathrm{n}+1}=\frac{1}{2}\left(\mathbf{W}_{\mathrm{i}, \mathrm{j}}^{\mathrm{n}}+\mathbf{W}_{\mathrm{i}, \mathrm{j}}^{\mathrm{n}+1 / 2}-\Delta t \operatorname{Res} \mathbf{W}_{\mathrm{i}, \mathrm{j}}^{\mathrm{n}+1 / 2}\right) .
$$

The Jameson's artificial dissipation model was applied to damp the oscillations.

$$
\begin{gathered}
\tilde{\mathbf{W}}_{\mathrm{i}, \mathrm{j}}^{\mathrm{n}+1}=\mathbf{W}_{\mathrm{i}, \mathrm{j}}^{\mathrm{n}+1}+A D\left(\mathbf{W}_{\mathrm{i}, \mathrm{j}}^{\mathrm{n}}\right), \\
A D\left(\mathbf{W}_{\mathrm{i}, \mathrm{j}}^{\mathrm{n}}\right)=C_{1} \psi_{1}\left(\mathbf{W}_{\mathrm{i}+1, \mathrm{j}}^{\mathrm{n}}-2 \mathbf{W}_{\mathrm{i}, \mathrm{j}}^{\mathrm{n}}+\mathbf{W}_{\mathrm{i}-1, \mathrm{j}}^{\mathrm{n}}\right), \\
+C_{2} \psi_{2}\left(\mathbf{W}_{\mathrm{i}, \mathrm{j}-1}^{\mathrm{n}}-2 \mathbf{W}_{\mathrm{i}, \mathrm{j}}^{\mathrm{n}}+\mathbf{W}_{\mathrm{i}, \mathrm{j}-1}^{\mathrm{n}}\right)
\end{gathered}
$$




$$
\begin{aligned}
& \psi_{1}=\frac{\left|p_{\mathrm{i}+1, \mathrm{j}}^{\mathrm{n}}-2 p_{\mathrm{i}, \mathrm{j}}^{\mathrm{n}}+p_{\mathrm{i}-1, \mathrm{j}}^{\mathrm{n}}\right|}{\left|p_{\mathrm{i}+1, \mathrm{j}}^{\mathrm{n}}\right|+\left|p_{\mathrm{i}, \mathrm{j}}^{\mathrm{n}}\right|+\left|p_{\mathrm{i}-1, \mathrm{j}}^{\mathrm{n}}\right|}, \\
& \psi_{2}=\frac{\left|p_{\mathrm{i}, \mathrm{j}+1}^{\mathrm{n}}-2 p_{\mathrm{i}, \mathrm{j}}^{\mathrm{n}}+p_{\mathrm{i}, \mathrm{j}-1}^{\mathrm{n}}\right|}{\left|p_{\mathrm{i}, \mathrm{j}+1}^{\mathrm{n}}\right|+\left|p_{\mathrm{i}, \mathrm{j}}^{\mathrm{n}}\right|+\left|p_{\mathrm{i}, \mathrm{j}-1}^{\mathrm{n}}\right|} .
\end{aligned}
$$

\subsection{Boundary conditions}

Inlet boundary conditions were realized for inviscid flow as follow: inlet velocity $M a_{\infty}$ together with angle of attack $\alpha$, density $\rho_{\infty}$ and total energy per volume $e_{\infty}$ were set; pressure $p_{\infty}$ was extrapolated from the flow field. In a case of viscous flow the inlet pressure $p_{\infty}$ was set.

Outlet boundary conditions were the same for the both type of flow. Outlet pressure was set and other variables extrapolated from the flow field.

Solid wall condition was realized by the adding of virtual cells. In a case of inviscid flow velocity components were prescribed so that sum of velocity vectors equals zero in its tangential component. In a case of viscous flow velocity components were prescribed so that sum of velocity vectors equals zero on the wall.

\section{Numerical results and discussion}

Mach number isolines are shown in all pictures together with inlet flow parameters below where $M a_{\infty}$ corresponds to the inlet Mach number and $\alpha$ is attack angle of inlet flow. Numerical results were validated for different setting of artificial dissipation to damp the oscillations and in a case of viscous model the influence on the physical viscosity was checked.

The set of the following six figures corresponds with results of the calculation of transonic inviscid flow for NACA 0012 and RAE 2822 airfoil respectively. This configuration was set as a reference for the testing of behaviour of the inviscid model with regarding to the proper setting of the artificial dissipation. Mach number isolines and pressure coefficient $C_{\mathrm{p}}$ are compared with [2].

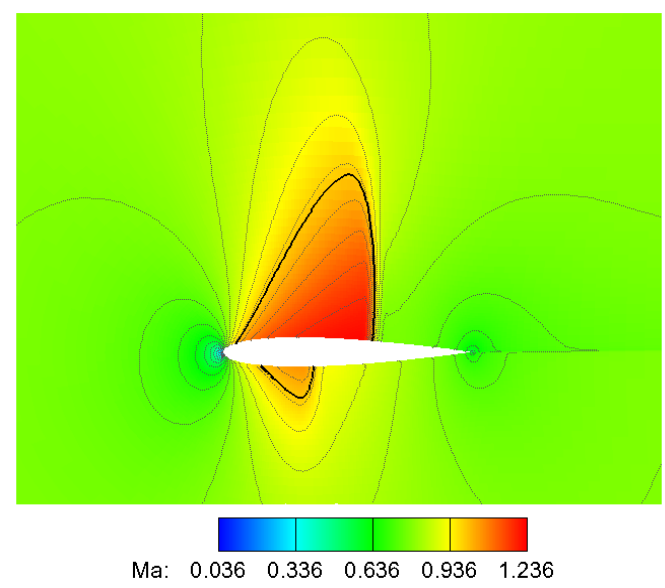

Figure 1. NACA 0012 airfoil, inviscid flow, $M a_{\infty}=0.8, \alpha=$ $1.25^{\circ}$, Mach number isolines

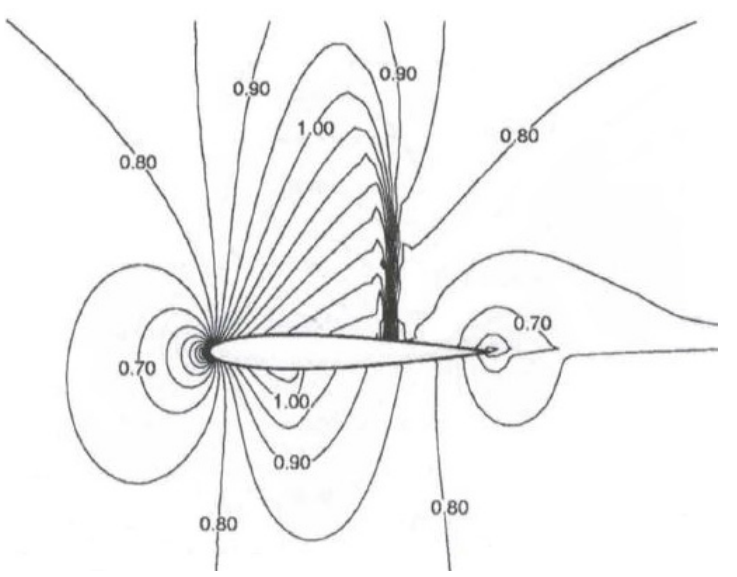

Figure 2. NACA 0012 airfoil, inviscid flow, $M a_{\infty}=0.8, \alpha=$ $1.25^{\circ}$, Mach number isolines by [2]

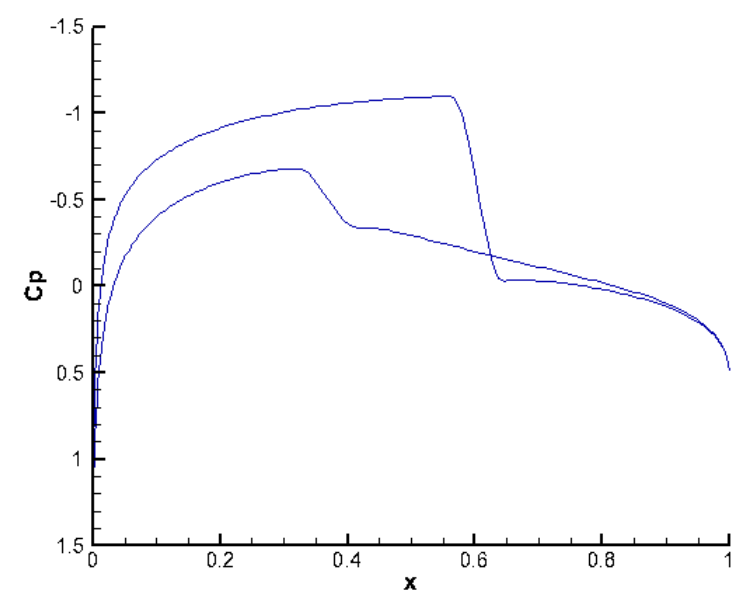

Figure 3. NACA 0012 airfoil, inviscid flow, $M a_{\infty}=0.8, \alpha=$ $1.25^{\circ}$, pressure coefficient $C_{\mathrm{p}}$ along the profile

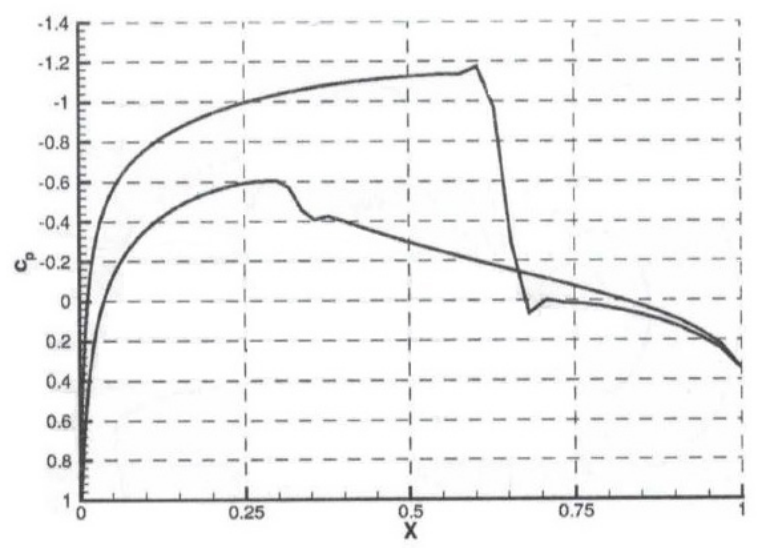

Figure 4. NACA 0012 airfoil, inviscid flow, $M a_{\infty}=0.8, \alpha=$ $1.25^{\circ}$, pressure coefficient $C_{\mathrm{p}}$ along the profile by [2] 


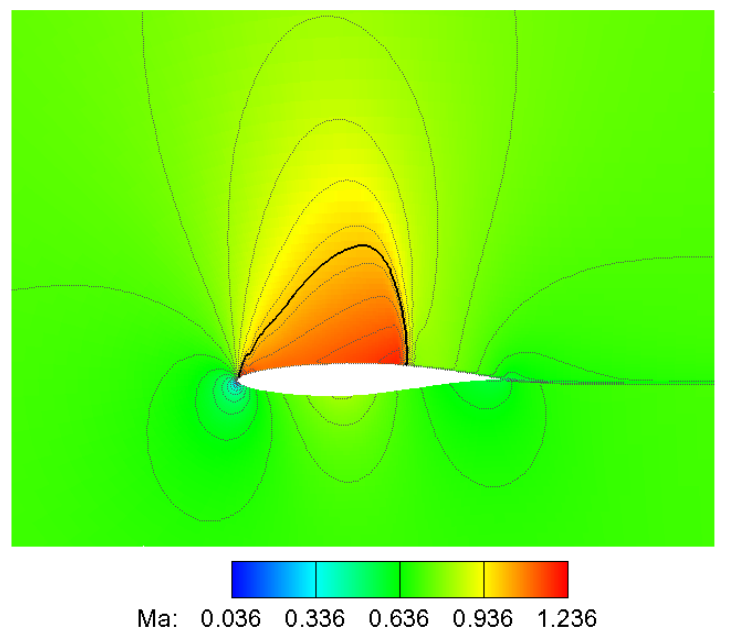

Figure 5. RAE 2822 airfoil, inviscid flow, $M a_{\infty}=0.73$, $\alpha=2.79^{\circ}$, Mach number isolines

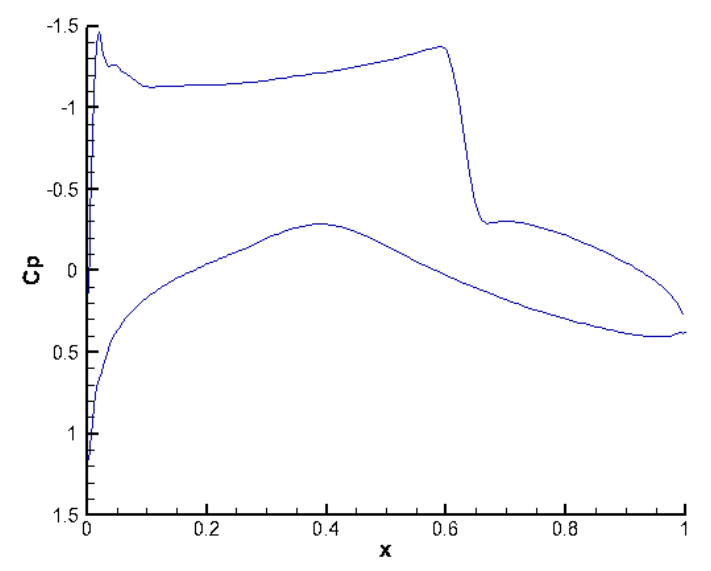

Figure 6. RAE 2822 airfoil, inviscid flow, $M a_{\infty}=0.73, \alpha=$ $2.79^{\circ}$, pressure coefficient $C_{\mathrm{p}}$ along the profile

The next set of figures shows some test cases of viscous laminar and turbulent flow. First set of figures shows laminar flow around the NACA 0012 airfoil for the inlet Mach number $M a_{\infty}=0.85$ with angle of attack $\alpha=0.0^{\circ}$ and Reynolds number $R e=500$. The case is quite far from the real physical conditions but it is generally used as the test case for the laminar model validation. Quite good result is clear and can be compared e.g. with results in [2]. The other figures show comparison between the used two different models of turbulence and experimental data. Inlet Mach number is $M a_{\infty}=0.15$ with angle of attack $\alpha=0.0^{\circ}$ and Reynolds number $R e=2.88 \times 10^{6}$. It is seen good correlation to the each other.

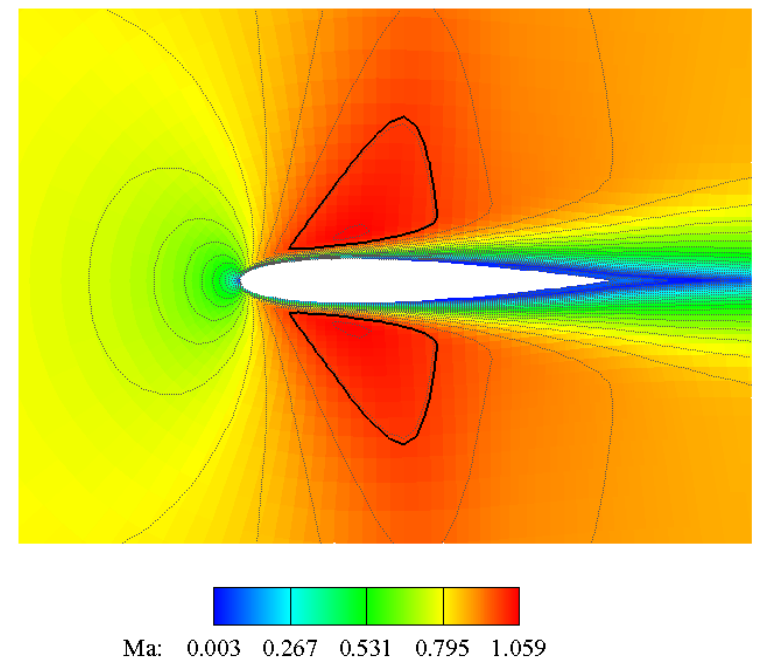

Figure 7. NACA 0012 airfoil, viscous laminar flow, $M a_{\infty}=$ $0.85, \alpha=0.0^{\circ}, R e=5 \times 10^{2}$, Mach number isolines

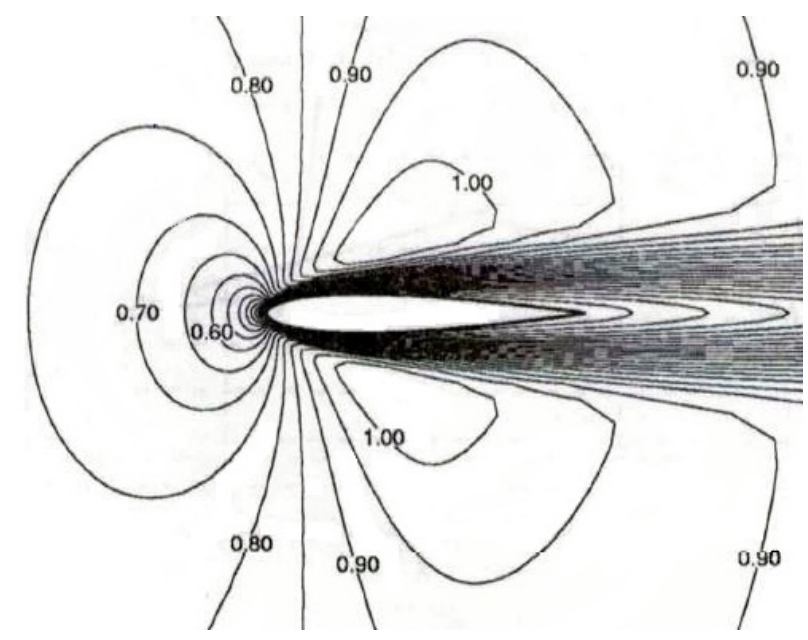

Figure 8. NACA 0012 airfoil, viscous laminar flow, $M a_{\infty}=$ $0.85, \alpha=0.0^{\circ}, \operatorname{Re}=5 \times 10^{2}$, Mach number isolines by [2]

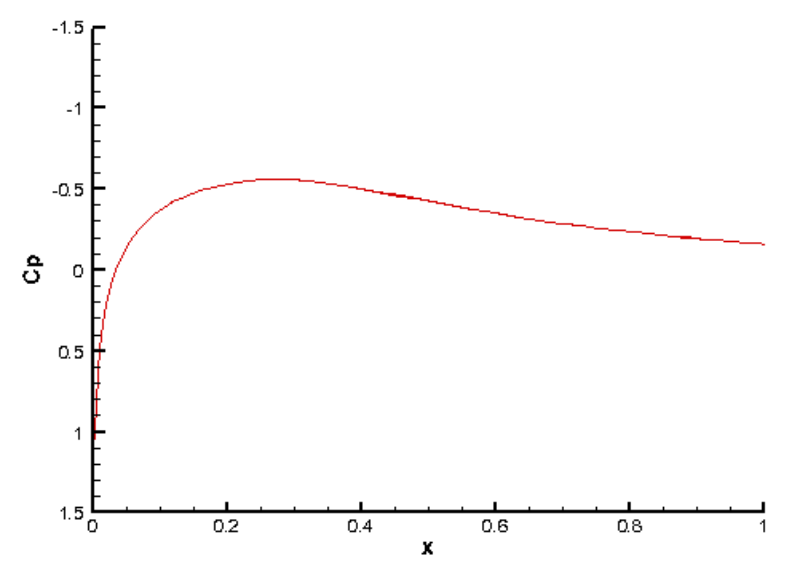

Figure 9. NACA 0012 airfoil, viscous laminar flow, $M a_{\infty}=$ $0.85, \alpha=0.0^{\circ}, R e=5 \times 10^{2}$, pressure coefficient $C_{\mathrm{p}}$ along the profile 


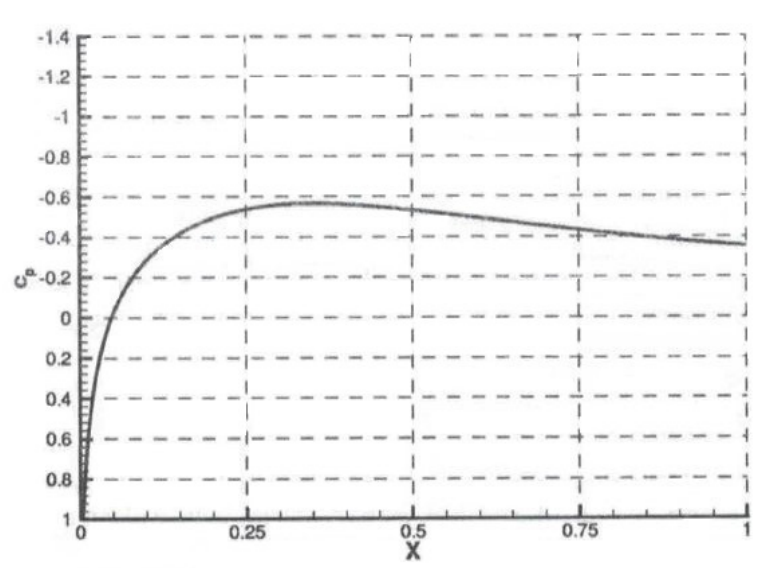

Figure 10. NACA 0012 airfoil, viscous laminar flow, $M a_{\infty}=0.85, \alpha=0.0^{\circ}, R e=5 \times 10^{2}$, pressure coefficient $C_{\mathrm{p}}$ along the profile by [2]

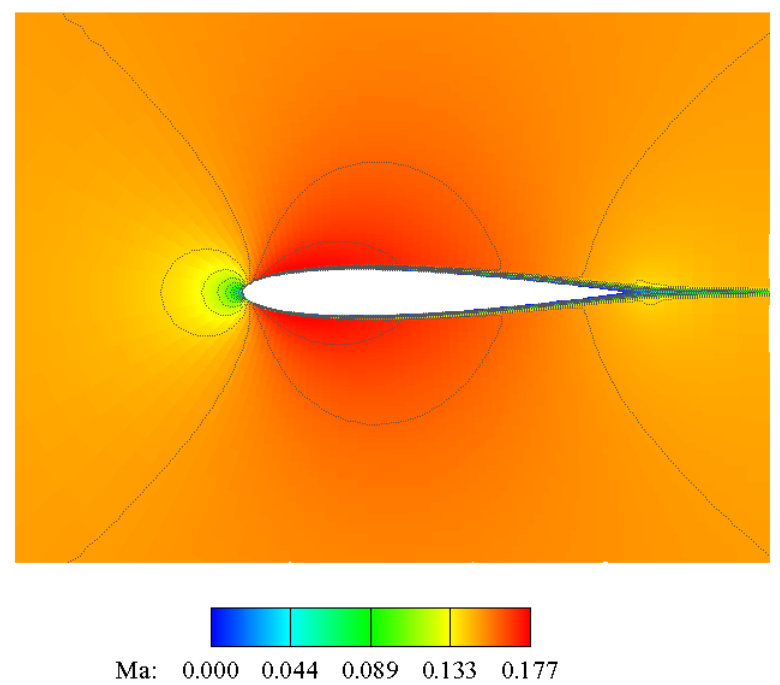

Figure 11. NACA 0012 airfoil, viscous turbulent flow, B-L model, $M a_{\infty}=0.15, \alpha=0.0^{\circ}, R e=2.88 \times 10^{6}$, Mach number isolines

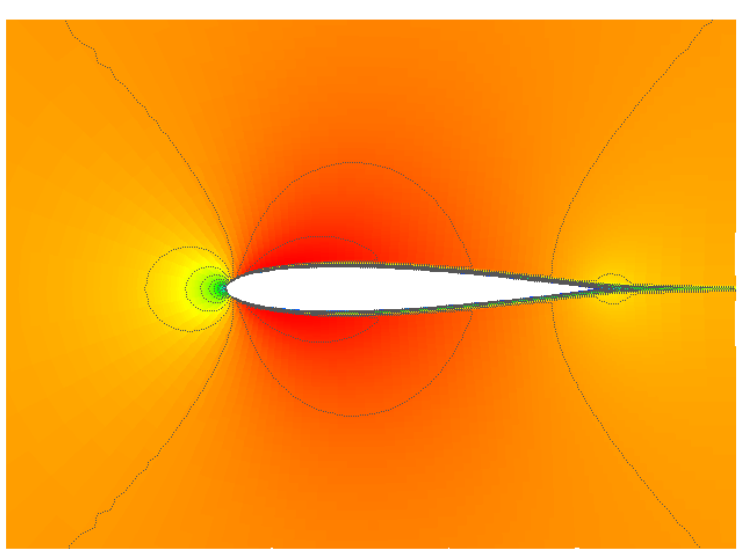

Ma: $\quad 0.000 \quad 0.044 \quad 0.088 \quad 0.132 \quad 0.176$

Figure 12. NACA 0012 airfoil, viscous turbulent flow, Wilcox k- $\omega$ model, $M a_{\infty}=0.15, \alpha=0.0^{\circ}, R e=2.88 \times 10^{6}$, Mach number isolines

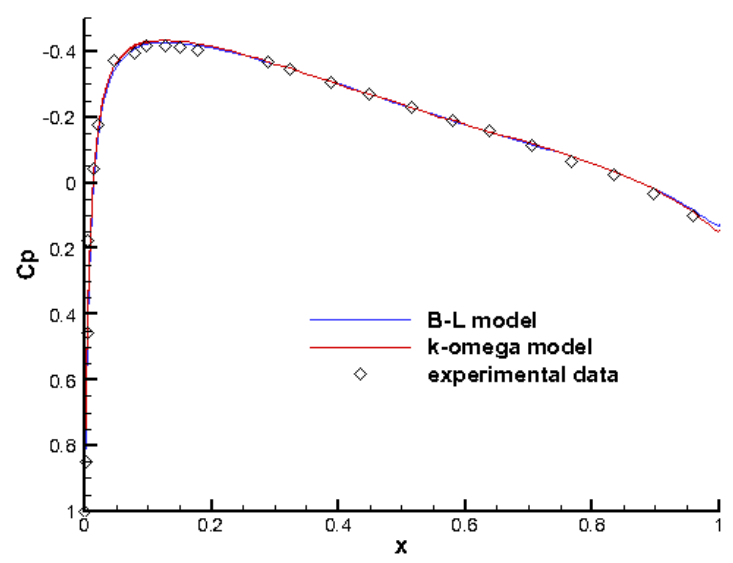

Figure 13. NACA 0012 airfoil, viscous turbulent flow, $M a_{\infty}=0.15, \alpha=0.0^{\circ}, R e=2.88 \times 10^{6}$, pressure coefficient $C_{\mathrm{p}}$ along the profile

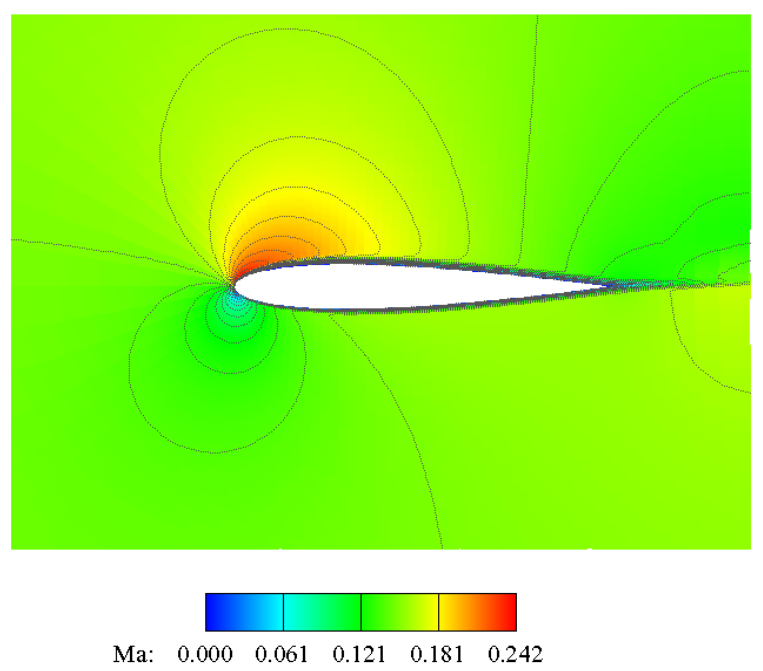

Figure 14. NACA 0012 airfoil, viscous turbulent flow, Wilcox k- $\omega$ model, $M a_{\infty}=0.15, \alpha=10.0^{\circ}, R e=2.88 \times 10^{6}$, Mach number isolines

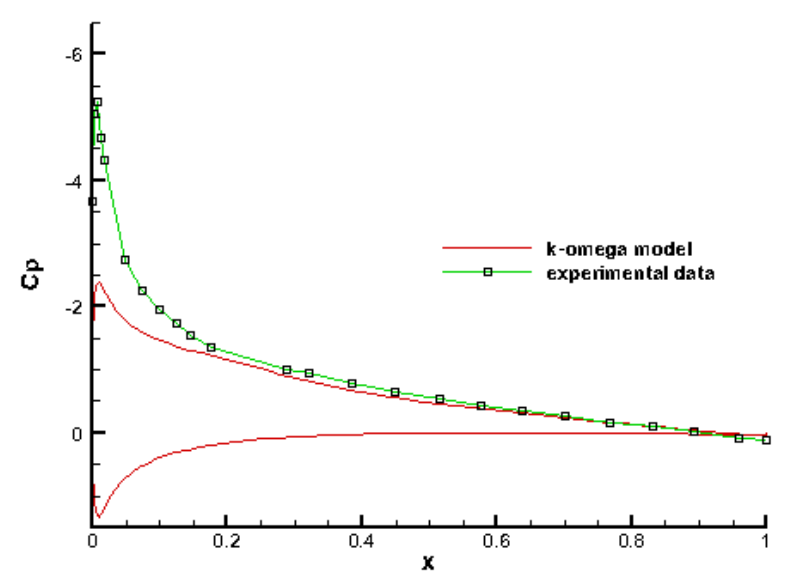

Figure 15. NACA 0012 airfoil, viscous turbulent flow, Wilcox k- $\omega$ model, $M a_{\infty}=0.15, \alpha=10.0^{\circ}, R e=2.88 \times 10^{6}$, pressure coefficient $C_{\mathrm{p}}$ along the profile 
The results of turbulent flow around the NACA 0012 profile are shown also at the figures above. In this case inlet Mach number was set to $M a_{\infty}=0.15$ and angle of attack $\alpha=10.0^{\circ}$, Reynolds number $R e=2.88 \times 10^{6}$. Pressure coefficient is compared with experimental data by [3] for the upper surface with free transition. The deviation close the leading edge is visible and needs to be more investigated. It can be caused e.g. by coarse grid spacing in $\mathrm{x}$ axis around the leading edge. Also the problem of artificial dissipation model needs to be solved in the next study to reduce the influence of additional numerical viscosity that could be also the source of incorrect behaviour.

\section{Conclusions}

The developed software was successfully tested for some basic types of the calculations of inviscid and viscous turbulent flow around the NACA 0012 and RAE 2822 airfoil. Deeper testing still needs to be done in a case of viscous turbulent flow to verify the possibilities of different numerical approaches as well as the testing of another modification of two-equation k- $\omega$ model. Also the deeper investigation will be done at a field of the transition between the laminar and turbulent flow.

\section{Acknowledgements}

The research has been financed in part by grants P 101/10/1329 and P 101/12/1271 and by the Education for Competitiveness Operation Programme.

\section{References}

1. D. C. Wilcox, AIAA J., 46, 2823, (2008)

2. J. Fort, K. Kozel, J. Fürst, J. Halama, J Dobes Num. solution of flow problems I (CTU in Prague, Prague 2004)

3. N. Gregory, C. L. O'Reilly, NASA R\&M, 3726, (1970)

4. R. Dvorak, K. Kozel, Mathematical modelling in aerodynamics (CTU in Prague, Prague, 1996)

5. R. Dvorak, Transonic Flows (Academia, Prague, 1986)

6. M. Slouka, K. Kozel, Topical Problems of Fluid Mech. 2014, 127-130 (2014)

7. M. Slouka, K. Kozel, Topical Problems of Fluid Mech. 2013, 57-60, (2013)

8. M. Slouka, K. Kozel, Fluid Dynamics 2013, 29-30, (2013) 